\title{
CONTROL AND EFFECTIVENESS IN A VOLUNTARY ORGANIZATION ${ }^{1}$
}

\author{
ARNOLD S. TANNENBAUM
}

\section{ABSTRACT}

A probability sample of the relatively autonomous local Leagues within the League of Women Voters of the United States was used to test two hypotheses concerning the causes and effects of varying patterns of control in organizations. Both are stated in terms of dimensions of the descriptive technique known as the "control graph." The hypotheses state that the effectiveness of the local League will vary directly with the average positive slope and the height of the local League's control curves. The data at least partially support the hypotheses.

While the literature of social science is rich in provocative ideas concerning the causes and effects of varying patterns of control, much remains to be done in testing empirically some of the many hypotheses formulated around this concept. The classic research of Lewin, Lippitt, and White is an early attempt to study in the laboratory the effects of varying patterns of control on children in groups. ${ }^{2}$ A number of studies have since been performed in laboratory as well as in field settings. The experiment by Coch and French in a textile manufacturing plant and that of Morse and Reimer in a large clerical organization illustrate the extension of this work into organizations. ${ }^{3}$ The study to be reported

\footnotetext{
${ }^{1}$ This article was prepared as part of a program of research on control in social organizations under a grant from the Carnegie Corporation to the Survey Research Center, Institute for Social Research, University of Michigan. The data were collected within a larger study of voluntary organizations supported by a grant from the Schwarzhaupt Foundation. I acknowledge the valuable contribution of Marjorie N. Donald and Robert L. $\mathrm{Kahn}$ in the research and would also like to thank Rensis Likert, Carol Livingstone, Donald Pelz, and Clagett Smith for their helpful suggestions.
}

${ }^{2}$ Ronald Lippitt and Ralph K. White, "An Experimental Study of Leadership and Group Life," in G. E. Swanson, T. M. Newcomb, and E. L. Hartley (eds.), Readings in Social Psychology (2d ed.; New York: Henry Holt \& Co., 1953), pp. 34054.

${ }^{3}$ Lester Coch and John R. P. French, Jr., "Overcoming Resistance to Change," Human Relations, I (November, 1948), 512-32; and Nancy C. Morse and Everett Reimer, "The Experimental Change of a Major Organizational Variable," Journal of $A b$ normal and Social Psychology, LII (January, 1956), 120-29. here, conducted among a number of local Leagues within the League of Women Voters of the United States, has been designed to extend some implications of the earlier research.

The descriptive model to be employed, called the "control graph," has been discussed and illustrated in earlier publications. ${ }^{4}$ It is designed to characterize the pattern of control in formal organizations. Its horizontal axis represents the various hierarchical levels in an organization: in an industrial organization, for example, the rank-and-file workers as a group would be placed at the bottom, followed by the foremen, managers, general managers, etc., up to the board of directors and chairman of the board at the top. The vertical axis represents the amount of control exercised by those at each of these hierarchical levels, that is, how much effect each level has in determining the organization's policies and actions. Various shapes of curve might be generated from the axes, depending on the amount of control of each level. For illustration, four prototypic models can be envisioned. In one the amount of control rises with hierarchical ascent; we might call this the "autocratic" or "oligarchic" model. Another curve declines with hierarchical ascent; it describes the "demo-

- See, e.g., Arnold S. Tannenbaum and Basil Georgopoulos, "The Distribution of Control in Formal Organizations," Social Forces, XXXVI (October, 1957), 44-50; and Arnold S. Tannenbaum and Robert L. Kahn, "Organizational Control Structure: A General Descriptive Technique as Applied to Four Local Unions," Human Relations, X (May, 1957), 127-40. 
cratic" model. If the uppermost level of the hierarchy is placed at the left end of the horizontal axis, the "autocratic" model would be characterized by a negative, and the "democratic" model by a positive, slope. However, some curves might remain fairly flat; that is, they have a zero slope. Flat curves might intersect the vertical axis at a point high or low on this axis. The low curve, indicating relatively little control by any hierarchical level, describes the "laissez faire" or "anarchic" model. The high curve, indicating a high level of control by all hierarchical levels, is called the "polyarchic" model.

Two aspects of organizational control structure are indicated by the control curve: the hierarchical distribution of control, represented by the shape or slope of the curve, and the total amount of control exercised by all levels in the organization, represented by the general height of (or area under) the curve. The fact that these dimensions may vary independently emphasizes the importance of distinguishing them. Organizations, for example, might have the same general distribution of control, while the total amount of control exercised within them differs sharply. On the other hand, organizations, though equal in the amount of control exercised within them, might differ markedly in the way it is distributed. Such variations have been found among the organizations to which the control graph has been applied, and it is in terms of these dimensions that the hypotheses of the present study are formulated:

Hypothesis 1.-Organizational effectiveness will be related directly to degree of positive slope of the control curve.

$H y$ pothesis 2.-Organizational effectiveness will be related directly to the average height of the control curve.

Organizational effectiveness is defined in terms of the means and ends of the organization. It is the extent to which an organization fulfils its objectives and preserves its means and resources. ${ }^{5}$
The first hypothesis is a recasting, in terms of the control graph, of the conviction that in our society the "democratic" type of organization will work more effectively than will the "autocratic." There are two kinds of reasons for making such a prediction under certain circumstances: those which apply to the maintenance of organizational resources and means and those which refer to the attainment of organizational goals.

1. In a culture where democratic values are extolled, rank-and-file influence is desired by a large proportion of members of organizations. Since relatively high rankand-file influence is desired by many as an end in itself, organizational control characterized by a positively sloped curve would be expected to contribute to the members' morale. Furthermore, having a say in determining the policies and actions of an organization may permit members to move the organization in directions which satisfy the needs of a fairly broad segment of them rather than the needs of the leaders. ${ }^{6}$ This assumes that the members have some understanding of the implications of the control they exercise and the skill and desire to exercise it effectively.

While a high degree of satisfaction among the members in itself is not considered a criterion of effectiveness, an organization with high morale will attract and retain members-a characteristic especially important to the maintenance of voluntary groups.

2. The exercise of control by lower echelons is likely to bring with it greater acceptance of jointly made decisions as well as an increased sense of responsibility and motivation to further the goals of the or-

\footnotetext{
${ }^{5}$ Basil Georgopoulos and Arnold S. Tannenbaum, "A Study of Organizational Effectiveness," American Sociological Review, XXII (October, 1957), 534-40.

${ }^{\circ}$ See, e.g., Morse and Reimer, op. cit.; and David L. Sills, The Volunteers: Means and Ends in a National Organization (Glencoe, Ill.: Free Press, 1957), p. 4.
} 
ganization. ${ }^{7}$ It may also provide, according to Likert, the means for effective coordination of the members' activity through the process of mutual influence. ${ }^{8}$ Some authors point out the detrimental effects of control from above. "Hierarchical authority" has been said, in a democratic society, to reduce initiative, inhibit identification with the organization, and to create conflict and hostility among members. ${ }^{9}$

While control from above has detrimental effects, it also seems, to some authors, to be necessary for efficient functioning. The detrimental effects can be mitigated under certain circumstances. Blau, for example, suggests the importance of minimizing the disruptive inequalities created by hierarchical authority. ${ }^{10}$ Sills sees the necessity of centralized control in the National Foundation for Infantile Paralysis but points to the importance of members' perception as a mitigating factor. Continued interest and participation in the Foundation by volunteers can be explained by the fact that nearly half the members believe that the organization is democratic, even though it is not. ${ }^{11}$

Another approach to this dilemma-the necessity of control from above together with the favorable effects of control from below-would consider the possibility of increasing the influence of lower levels in

${ }^{\text {? }}$ See, e.g., John R. P. French, Jr., Joachim Israel, and Dagfinn Ås, "An Experiment on Participation in a Norwegian Factory," Human Relations, XIII (February, 1960), 3-19; James G. March and Herbert A. Simon, Organizations (New York: John Wiley \& Sons, 1958), p. 54; and Morse and Reimer, op. cit.

${ }^{8}$ For a more detailed discussion of this point see Rensis Likert, "A Motivational Approach to a Modified Theory of Organization and Management," in Mason Haire (ed.), Modern Organization Theary (New York: John Wiley \& Sons, 1959), pp. 184-217.

${ }^{9}$ See. e.g., ibid., and Peter M. Blau, Bureaucracy in Modern Society (New York: Random House, 1956), p. 80.

${ }^{10}$ Blau, op. cit., pp. 82-83.

${ }^{11}$ Sills, op. cit., p. 219; see also March and Simon, op. cit., p. 54 . an organization without decreasing that of upper-echelon personnel-of increasing the average height as well as the degree of positive slope of the control curve. This leads to Hypothesis $2 .{ }^{12}$

Two aspects of this relationship should be considered: one in which total control can be seen as an effect and one in which it is a cause of (or "intervening variable" in relation to) effectiveness.

1. The hypothesis that total control is a cause of organizational effectiveness is based on an elementary assumption regarding organization: Organized behavior is predicated on the co-ordination of individual behavior in some form of concerted action toward a goal or set of goals. This requires adherence to rules, conformity to organizational law, formal and informal: in other words, it requires control. Discussions of control in organizations, however, often assume a reciprocal relationship between the control exercised by upper and that exercised by lower levels of the hierarchy. Increasing the influence of one group implies decreasing the influence of another. The weakness of this view, however, becomes apparent when one considers the laissez faire organization, which represents the limiting case in which little or no control is exercised and in which little external direction or internal co-ordination will be manifest.

One can readily imagine moving in any of several possible directions away from the laissez faire condition: by increasing the control exercised by upper-echelon personnel, by increasing that of lower-level personnel, or by increasing the influence

${ }^{12}$ Aspects of Hypothesis 2 have been elaborated in earlier publications; e.g., Rensis Likert, "Influence and National Sovereignty," in John G. Peatman and Eugene L. Hartley (eds.), Festschrift for Gardner Murphy (New York: Henry Holt \& Co., 1960) ; Arnold S. Tannenbaum, "Control Structure and Union Functions," American Journal of Sociology, LXI (May, 1956), 536-45; and Arnold S. Tannenbaum and Robert L. Kahn, Participation in Union Locals (Evanston, Ill.: Row, Peterson \& Co., 1958). 
of both. ${ }^{13}$ If, as some authors contend, a high degree of control by the leaders is necessary for the efficient administration of organizations, and if, on the other hand, a high degree of control by the members is also necessary to foster identification, motivation, and loyalty, why would not substantial control exercised by both create conditions for more effective performance? Likert has suggested the importance of high "mutual influence" at all levels within organizations as the basis of the effective co-ordination of organizational activity as well as for the integration of the goals of individual members and of the organization. ${ }^{14}$ This condition, leading to effective performance, entails significant control exercised by persons at all levels, the leaders as well as the rank and file. Furthermore, employing the control-graph method, Likert has found a direct relationship between effectiveness (measured in terms of productivity and other criteria) and height of control curve among thirty-one plants of an industrial organization. ${ }^{15}$

2. The hypothesis that a high degree of total control may be a result of organizational effectiveness follows from the assumption that all organizations have functions to perform, and rewards (of one kind or another) to dispense. The effective or-

\footnotetext{
${ }^{13}$ Several authors illustrate in different ways the phenomenon of increased total control; e.g., March and Simon's discussion of "participative management" "where there is participation, alternatives are suggested in a setting that permits the organizational hierarchy to control (at least in part) what is evoked. 'Participative management' can be viewed as a device for permitting management to participate more fully in the making of decisions as well as a means for expanding the influence of lower echelons in the organization" (op. cit., p. 54). Selznick's "co-optation principle" would seem to imply, at least under some circumstances, a degree of influence exercised within the organization by the co-opted element (which it did not exercise before co-optation) as well as an increased control by the "hierarchy" over the co-opted element (Philip Selznick, TVA and the Grass Roots [Berkeley: University of California Press, 1953], pp. 1316, 259-61).
}

${ }^{14}$ Likert, "A Motivational Approach ...., op. cit., "Influence and National Sovereignty," op. cit. ganization, by definition, is more likely to achieve its goals. It is also likely to have a greater stock of disposable rewards. Both organizational goals and rewards are likely to be relevant to the interests, if not the welfare, of members as well as leaders, and the amount of control which they try to exercise may be affected accordingly. Control in the effective organization is attractive to members and leaders alike because it is instrumental to the achievement of important satisfactions. The ineffective organization, on the other hand, has relatively little to offer. The rewards of control, and, consequently, the motivation to exercise control, are correspondingly less.

\section{THE LEAGUE OF WOMEN VOTERS OF THE UNITED STATES, IN 1956}

The League of Women Voters of the United States includes over 100,000 members organized into about one thousand relatively autonomous local Leagues around the country. These local Leagues, which vary in size from about 25 to 3,000 members, form the units of the present study.

The League is a non-partisan political organization. Its general purpose is "to promote political responsibility through informed and active participation of citizens in government." Its activities include selecting and studying public issues, declaring a position on some of them, bringing them to the attention of the public, and supporting legislation in line with their stand. In addition, the organization informs the public about the mechanics of voting and supplies information on issues on which the League may not have taken

\footnotetext{
${ }^{15}$ Some of these data are reported by Rensis Likert ("Influence and National Sovereignty," $o p$. cit). We would suspect that too much control may be as dysfunctional as too little, and a hypothesis more general than that offered above would specify an optimum level of control above or below which the organization would function below its potential. We are not yet in a position to specify the optimum for specific organizations. We can safely assume, however, that many, and particularly voluntary organizations, are operating at a level considerably below it.
} 
an official stand, as well as information about (but never in support of, or in opposition to) political candidates. Members also prepare publications, make occasional presentations to public groups, and conduct fund-raising campaigns and membership drives.

The business of the local League is carried out in part through several kinds of meetings, the most frequent of which are discussion groups. It is here that most of the study, discussion, and participation by members take place and that many decisions are made regarding policies and actions.

Members are strongly committed to the ideals of democratic government: they often refer to their organization as a kind of workshop in democracy. Its formally established decision-making machinery provides, in theory, ample opportunity for the members to exercise control over the affairs of their local organization. Many members and leaders are aware, however, that the actual local decision-making does not always conform to the ideal.

League members are an unusual group in several respects. About 50 per cent have completed college. In joining and participating, many feel they are doing something of real value in helping extend the spirit of responsible citizenship and good government. In addition, many join for personal or social reasons; they find it a welcome change from their regular household routine; they enjoy meeting other women and find the discussions interesting and edifying.

The hierarchical scale of the local League consists of an elected president at the top, a partly elected and partly appointed board of directors at an intermediate level, and the rank and file at the bottom. These three hierarchical levels form the basis for the horizontal axis of the control graph.

THE LEAGUE AS A FORMAL ORGANIZATION

The League has all of the characteristics of a formal organization. As a voluntary organization, however, it differs in certain respects from many other formal organizations: (1) The League's governmental structure is partly representational in nature, including elected as well as appointed leaders. Many aspects of policy-making are formally decentralized and in the hands of the rank and file. (2) League action follows a long process of interpersonal action; discussion and agreement are necessary and important in it. (3) Much of the League's effort is psychic rather than physical (to use the distinction of Ross). ${ }^{16}$ (4) The League's primary function involves working on and through people external to the organization and, to some extent, interacting and influencing other organizations. as is the case in unions and political organizations. (5) Membership in the League is open to all female citizens of voting age in the community. However, women who join tend to be educated, middle-income women, interested in public affairs. (6) Unlike some voluntary groups, the League de-emphasizes social interaction as an objective. Formally, the League is primarily a "social influence" rather than an "expressive" group (to use the distinction of Rose). ${ }^{17}$ The forms of sanctions, coercion, or pressure which can be applied to members to achieve conformity and activity are much more limited than they are in other organizations. (8) The League's ability to survive is largely a function of the members' willingness to do its work. It does not have to maintain a competitive advantage vis-à-vis other groups, as do profit-making organizations.

A probability sample of 104 local Leagues was drawn from a complete list of all Leagues in the country. A stratification

\footnotetext{
${ }^{16}$ Edward A. Ross, "The Organization of Effort," American Journal of Sociology, XXII (1916), 118; reprinted in Edgar F. Borgatta and Henry J. Meyer (eds.), Sociological Theory (New York: Alfred A. Knopf, Inc., 1956).

${ }^{17}$ Arnold Rose, Theory and Method in the Social Sciences (Minneapolis: University of Minnesota Press, 1954), p. 52.
} 
procedure by state and by size of League was employed so as to increase the accuracy of the sample. Each League was assigned a probability of falling into the sample proportional to its size. While 104 different Leagues fell into the sample, several of the very large Leagues were chosen more than once, and they therefore enter into the data more than once, making our total $N$ of sample choices 112. Ignoring these duplicate choices would have created some bias. The stratification procedures employed added accuracy to the sample, and they make our use of $N=$ 112 a good approximation. ${ }^{18} \mathrm{We}$ are thus projecting to a hypothetical population of Leagues which includes a somewhat greater proportion of large and a somewhat smaller proportion of small Leagues than exist in the population. ${ }^{19}$

Three basic sets of measures were employed:

\section{Measures of local League effective-} ness.-A score for each of the 104 Leagues was obtained through rating forms filled out by twenty-nine persons assigned by national headquarters. These persons qualified as experts through their experience in the organization at state or national levels and their familiarity with the work of many of the local Leagues.

In judging the over-all effectiveness of each of the Leagues, raters were asked to consider several criteria of effective functioning. These were based on a number of objectives established for Leagues by the national organization. They include the primary objectives of all Leagues: high quality and quantity of League publica-

\footnotetext{
${ }^{18} \mathrm{I}$ am indebted to Dr. Leslie Kish and Miss Irene Hess for the technical design of the sample.

${ }^{19}$ Choosing a sample in this way is justified on the grounds that very large Leagues are rare, and a simple random sample would not be likely to include any very large ones, and that a kind of proportional representation of Leagues in the results is achieved. Each League in the sample represents the same number of members. The greater weight and importance attached to the larger Leagues reflect the correspondingly larger proportion of members in these Leagues.
}

tions and significant impact of the League in its community. Also included are a number of objectives stated by the national organization which might be considered instrumental in nature: success of the League in fund-raising campaigns, the growth of the League and its size relative to the community, and the amount of activity of members and their knowledge of League activities.

A rating scale with landmark statements was provided as follows:

100-This is an excellent League-among the very best. It is outstanding and exemplary of what I think Leagues should be like. It is probably unlikely that we can get many Leagues to operate as well as this one.

75_-This is a good League. It is generally above average in the various standards which I feel apply to the evaluation of Leagues. If all locals were this good, the League of Women Voters of the United States would be much improved as an organization.

50_- This is a fair League - about average in the various standards of effective League operation. It does not stand out, however.

25-This is only moderate (mediocre) in that it meets most of the standards of League operation but falls below the average. It needs improvement more than most Leagues.

0 - This is a very poor League-as poor as one can get and still remain within the organization. It barely meets standards and falls below on most. It is considerably below average and would require drastic changes to bring it up to par.

Scores of effectiveness were computed for each League by averaging the ratings of each by all the judges who rated them. Some of the raters were not sufficiently familiar with all 104 Leagues to provide a rating of each; however, each League was rated by at least two raters, and many were rated by all. The scores derived in this way range from a low of 8 to a high of 100 . Their split-half reliability is .82 . The product-moment correlation between League effectiveness and size of League is 
.55. However, the relationship is not linear, and, when size of League is transformed logarithmically, the correlation becomes .74. Size, then, is an important component of League effectiveness. This is to be explained in terms of the greater impact which a large League is able to make within its community and within the national organization. It also reflects the ability of the League to get and hold members-an important criterion of effectiveness. However, size itself is likely to create important effects of its own quite apart from the question of effectiveness. In testing our hypotheses then, we shall control for the logarithm of size through partial correlation.

It might be argued that the raters of effectiveness are, in effect, judging aspects of control in the various Leagues, thus creating a spurious correlation between effectiveness and control. We shall therefore employ a supplementary and quite independent measure of League effectiveness, discussed below.

2. Measures of control in the Leagues. -A questionnaire was mailed to approximately twenty-five randomly chosen members in each of the sample Leagues, with the exception of the few large Leagues which were sampled more than once. Here, fifty or seventy-five questionnaires were administered according to the number of times these Leagues might have been chosen in the sample. A final response rate of 77 per cent was obtained. ${ }^{20}$ The total $N$ of respondents who returned questionnaires is 2,847 , but of this group about 15 per cent did not answer the relevant questions. This sample of respondents includes only rank-and-file members. The $N$ of organizational units, serving as the basis for the correlational tests employed, however, remains 112.

Each respondent was asked a set of

${ }^{20}$ After an elaborate set of follow-up procedures including letters and telephone calls by members of the research staff. I am indebted to Dr. Charles Cannell and to Miss Sharon Summers for their contribution to this phase of the research. questions concerning control in the local League. The question upon which the control graph is based was asked in tabular form (Table 1).

The amount of control exercised by each of the hierarchical levels in a given League is computed by averaging the judgments of all respondents regarding each of the levels. The independent-variable index for each League is obtained on the basis of these scores. A measure of the independent variable of Hypothesis 1 is derived by computing the slope of a best-fit straight line for the data of each League. This requires the admittedly crude but workable assumption of equal scale intervals along both the horizontal and vertical axes. Total control, the independent variable of Hypothesis 2, is obtained simply by adding the amounts of control exercised by the three hierarchical levels in each League as reported in response to the question (Table 1).

It might be argued that the predicted correlations obtained through the use of the above measures really reflect greater subjective feeling for "democratic" control among members of effective Leagues than there is among members of ineffective Leagues, rather than accurate appraisals of the objective situation in each League. We shall therefore employ the question: "In your opinion, how much influence do you think each of these groups should have in determining the policies and actions of your local League?" This is intended as a measure of the possible halo or response set in effective as compared to ineffective Leagues. The curves derived from this question are referred to as the "ideal control curves" as contrasted with the "actual control curves" based on the earlier question. The "ideal" question was asked immediately after the "actual" control question.

The response categories are precisely the same as those for the previous question. If a certain halo or response set in relation to control exists in effective as compared to ineffective Leagues, we would expect such 
differences to be reflected in the responses to the above question. We shall therefore be interested in the extent to which slope and height of control curve derived from this question correlate with effectiveness. Zero correlations would be most favorable to the original hypotheses.

In addition to the sample of rank-and-file members who serve as informants regarding control within each League, a sample of six board members in each League was also questioned. The correlations between the responses of these groups are smaller than was hoped, although they are all significant beyond the .05 level. The judgments of the rank and file and of board members regarding the control exercised ber of meetings (of several kinds) which they attend. These questions were formed into an index with a split-half reliability of .87 .

3. Supplementary measure of League effectiveness.-The ratings of effectiveness described above are subject to some of the limitations inherent in any measure based on judgment. We shall therefore retest our hypotheses, using an independent and behavioristic criterion of one aspect of effective League functioning: the proportion of sampled members in each League who filled out and returned the survey questionnaire. Although the job of completing the questionnaires was assigned by ourselves, this was clearly a task relevant to

TABLE 1

In general, how much influence do you think the following groups or persons actually have in determining the policies and actions of your local League?

\begin{tabular}{|c|c|c|c|c|c|}
\hline \multirow{4}{*}{$\begin{array}{l}\text { Your local president. } \\
\text { Your local board as a } \\
\text { group (excluding the } \\
\text { president)........ } \\
\text { Your local member- } \\
\text { ship as a whole (ex- } \\
\text { cluding the board). }\end{array}$} & $\begin{array}{c}\text { No } \\
\text { Influence }\end{array}$ & $\begin{array}{l}\text { A Little } \\
\text { Influence }\end{array}$ & $\begin{array}{c}\text { Some } \\
\text { Influence }\end{array}$ & $\begin{array}{l}\text { A Great } \\
\text { Deal of } \\
\text { Influence } \\
\end{array}$ & $\begin{array}{l}\text { A Very } \\
\text { Great } \\
\text { Deal of } \\
\text { Influence }\end{array}$ \\
\hline & & $\square$ & $\square$ & & \\
\hline & $\square$ & $\square$ & $\square$ & $\square$ & $\square$ \\
\hline & $\square$ & $\square$ & $\square$ & $\square$ & $\square$ \\
\hline
\end{tabular}

by the president correlate at .50 ; of the control exercised by the board, .18; and of the control by the membership, .25. Our measures are thus subject to some unreliability, and we shall therefore be interested in the extent to which our hypotheses are substantiated by using the judgments of board members as well as those of rankand-file members.

Finally, one might argue that the measures of control and of effectiveness are really measures of amount of activity by members and that the hypotheses are, in effect, tautologous. We shall evaluate the strength of this contention through the use of a direct measure of members' participation based on two questions dealing with the amount of time members spend in the activities of the organization and the num- the organization, since the research was designed to be of use to the League, and was officially indorsed by the national organization and the local Leagues. General appeals for co-operation were made at the outset by the national president through the national publication and by local officers through their own organs. The rate of returns is an especially interesting index of unit performance, since it represents, in the terms of Lewin, Lippitt, and White, a type of "leader-out" behavior-a task performed by members away from the direct supervision of leaders. ${ }^{21}$

We would expect that, if both the rate of questionnaire returns and the ratings of effectiveness are valid measures, they would be correlated positively. On the

${ }^{n}$ Lippitt and White, op. cit. 
other hand, we would be concerned about differences in rate of response between effective and ineffective Leagues as creating a possible contamination of the other relationships studied. The method of administration of the questionnaire and the follow-up procedures were designed to minimize this relationship. Two correlations are therefore of importance here: the correlation between the League's effectiveness and rate of return of questionnaires immediately before the follow-up procedures were initiated, and the correlation between this point is .33 , which is significant beyond the .001 level of confidence. The correlation, after all follow-ups were terminated, is .24. Although the correlation decreases slightly, it is not as low as might be hoped. There is a somewhat higher response rate from effective than from ineffective Leagues. These correlations nevertheless provide evidence for the validity of the scores of effectiveness.

Figure 1 shows the control curves, actual and ideal, averaged for all Leagues in

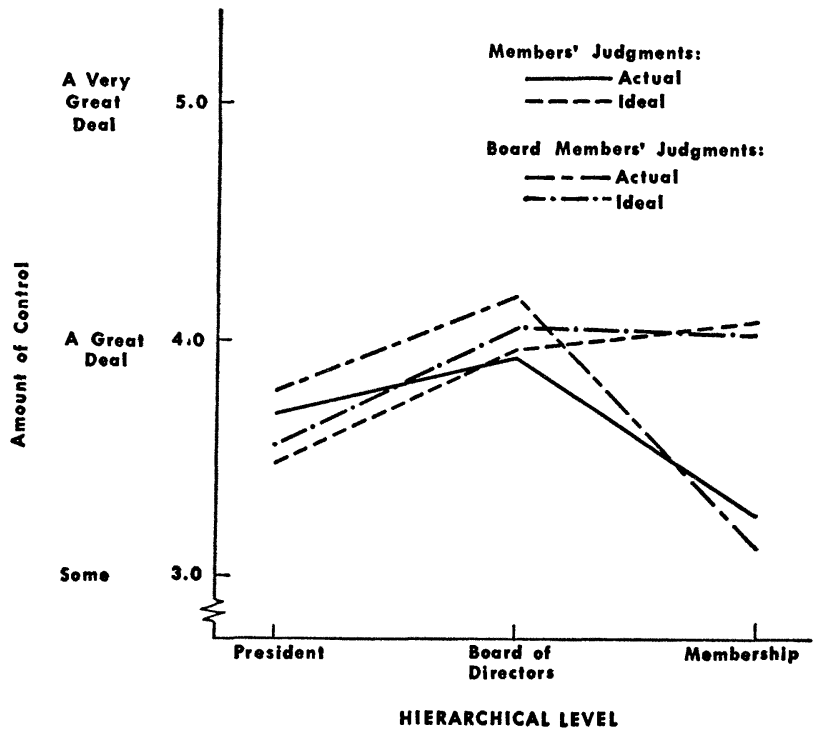

Fig. 1.-Control curves, actual and ideal, averaged for all Leagues, based on the judgments of members and board members.

effectiveness and final rate of returns. The former, if positive and significant, reflects the validity of the scores of effectiveness; the latter provides some indication of the success (or lack thereof) of the follow-up procedures, as well as the extent to which differential response rate may enter as a possible contamination in the relationships studied.

Prior to the follow-up procedures, 49.7 per cent of the questionnaires were returned. The partial correlation (holding the logarithm of size constant) between League effectiveness and rate of returns at the sample. Curves based on the judgments of rank-and-file members and of board members are drawn separately. Both the "actual" curves tend to be negatively sloped. ${ }^{22}$ By way of contrast, the "ideal" curves are positively sloped. This conforms to the generally recognized ideal for the organization. The sharp differences be-

\footnotetext{
${ }^{22}$ Our hypotheses are thus to be tested among organizational units which have predominantly negatively sloped control curves. When we refer, then, to increases in degree of positive slope, we understand this to be equivalent to decreases in degree of negative slope.
} 
tween the "ideal" and "actual" curves suggest that the respondents are making an important distinction in their responses to these questions between how, in their opinion, the organization should work and how it actually does.

Table 2 presents the partial correlations in a test of our hypotheses. The data support each. Effectiveness of the League is significantly related to the slope $\left(r_{p}=\right.$ $.31)$ and average height $\left(r_{p}=.29\right)$ of the control curve based on judgments of members. Furthermore, the correlations between effectiveness and the slope and height of the "ideal" control curve are not the correlation between total control and effectiveness is .26 , holding slope and size constant. Both are significant beyond the .005 level of confidence. An approximation of the multiple correlation using both slope and total control as the independent variables, and holding the logarithm of size constant, yields a value of .42 , suggesting some advantage to predicting effectiveness from both slope and height of control curve rather than one or another separately. ${ }^{23}$

Nor are these results to be explained in terms of the differential rate of return of questionnaires in effective and ineffective Leagues. For example, the correlation be-

TABLE 2

Partial Correlations between EFFeCtiveness and Aspects of CONTROL in Leagues, Holding Size of League Constant

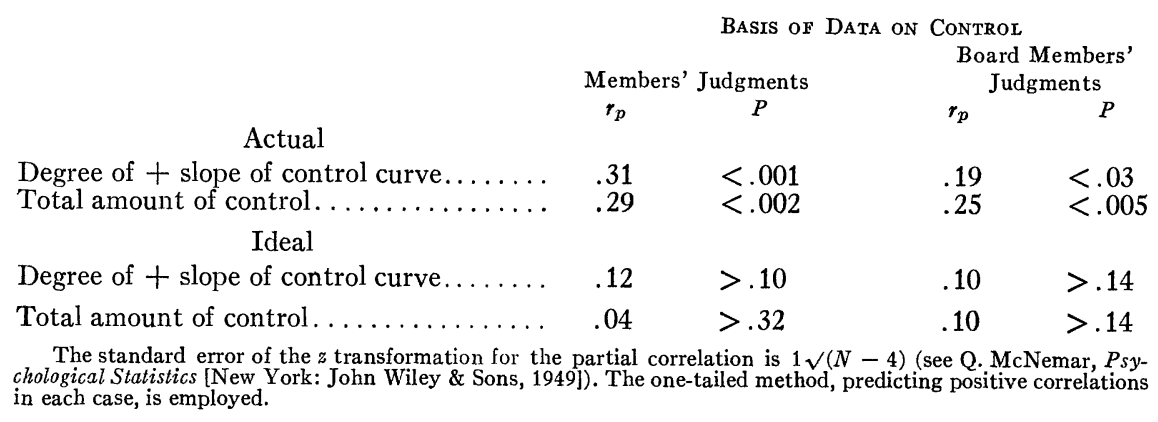

significantly different from zero. When the judgments of board members are employed as the basis for measuring the independent variables, the correlations are .19 between slope and effectiveness and .25 between total amount of control and effectiveness. Although modest in size, these correlations are statistically significant. The "ideal" data as reported by board members yield essentially the same results as that reported by the members.

The correlation between total control and slope (based on members' judgments) is only .14 , indicating that we are testing two distinct hypotheses. This is further substantiated by second-order partial correlations. For example, the partial correlation between slope and effectiveness is .28, holding size and total control constant; tween slope and effectiveness is .28 , and that between total control and effectiveness, .24, when size and final rate of returns are partialed out. Both correlations are significant at beyond the .005 level of confidence.

Finally, let us consider the possibility that the measures of control and of effectiveness are really measures of members' participation and that the hypotheses are, for this reason, tautologous. The correlation between members' participation and effectiveness, holding League size constant, is .18 . This is a relatively small but statistically significant relationship. Participa-

${ }^{23}$ Frederic M. Lord, "Nomograph for Computing Multiple Correlation Coefficients," Journal of the American Statistical Association, L (December, 1955), 1073-77. 
tion by members also correlates significantly with slope of control curve $\left(r_{p}=\right.$ .38) but not with height of control curve $\left(r_{p}=.05\right) .{ }^{24}$ However, partialing-out the effects of members' participation (as well as size) does not destroy the relationship between each of the two control indexes and effectiveness. These second-order partials yield values of .26 and .28 respectively for slope and height of control curve as independent variables $(p<.003)$. On the other hand, partialing-out slope of control curve reduces the correlation between members' participation and effectiveness to .07. This argues against the contention that participation by members explains the
In general, Leagues that are high or medium on both degree of positive slope and total control are likely also to be high in effectiveness. Furthermore, increasing the value of either one of the independent variables while decreasing the other does not seem to be accompanied predictably by increases in effectiveness. The effects of variations on one variable may be different when the second is held constant at a high level, as compared to when it is held low; for example, decreasing the total amount of control appears to be accompanied by decreasing effectiveness when degree of positive slope is relatively high, but not when it is low. Likewise, decreasing the

TABLE 3

Percentage of Leagues Which ARe above Median in Effectiveness,* FOR VARYING COMBINATIONS OF SLOPE AND TOTAL CONTROL

\begin{tabular}{|c|c|c|c|c|c|c|c|}
\hline \multirow{2}{*}{$\begin{array}{l}\text { DegRee of Positive } \\
\text { SLOPE }\end{array}$} & (11 & $\begin{array}{l}\text { High } \\
.2-12.2)\end{array}$ & & $\begin{array}{l}\text { Total C } \\
\text { [edium } \\
7-11.1)\end{array}$ & & $\begin{array}{l}\text { Low } \\
7-10.6)\end{array}$ & \multirow[b]{2}{*}{$N$} \\
\hline & $N$ & Per Cent & $N$ & Per Cent & $N$ & Per Cent & \\
\hline$\underset{\text { Medium }}{\operatorname{High}}(-.05-+.35) \ldots$ & 14 & 78 & 13 & 69 & 8 & 50 & 35 \\
\hline $\begin{array}{r}(-.06-.25) \ldots \ldots \\
\text { Low }(-.26--.85) \ldots\end{array}$ & $\begin{array}{r}13 \\
9\end{array}$ & $\begin{array}{l}62 \\
33\end{array}$ & $\begin{array}{l}12 \\
17\end{array}$ & $\begin{array}{l}75 \\
41\end{array}$ & $\begin{array}{l}15 \\
11\end{array}$ & $\begin{array}{l}13 \\
36\end{array}$ & $\begin{array}{l}40 \\
37\end{array}$ \\
\hline Total N....... & 36 & & 42 & & 34 & & 112 \\
\hline
\end{tabular}

relationship between slope and effectiveness, and it suggests, on the contrary, that the small degree of association between participation and effectiveness is to be explained in terms of a certain degree of control by the membership implicit in some activities of members.

A further impression of the joint effects of slope and of total control can be obtained from Table 3 , in which are presented the proportions of Leagues that are above median effectiveness under varying combinations of slope and total control (based on members' judgments).

\footnotetext{
${ }^{24}$ The near zero correlation between total control and participation by members is not consistent with the results of an earlier study of four local unions (Tannenbaum, "Control Structure ....," $o p$. cit.; and Tannenbaum and Kahn, Participation in Union Locals).
}

degree of positive slope appears more predictably related to decreasing effectiveness when total control is high than when it is low. A type of threshold is suggested by these data: a minimum level of total control and of degree of positive slope may be necessary for effective performance. If the appropriate threshold is not met by one of these variables, increasing the other does not seem to help. For example, the performance of laissez faire (low total control) Leagues may not be much improved by making them more "democratic" (positively sloped) without at the same time making them less laissez faire.

Table 4 presents the correlations between initial rate of questionnaire returns as a criterion of the effectiveness of the local League and the respective dimensions 
of the control curve. The results based on the responses of members and board members are quite similar. They both offer further support for Hypothesis 1 but not for Hypothesis 2. However, when the dependent variable is interpreted simply as a type of "leader-out behavior" (rather than as an adequate measure of League effectiveness) the results make sense. They are consistent with the early observation of Lewin, Lippitt, and White: the "democratic" organization is more productive than is the "autocratic" when the leader is absent. However, productivity under leader(and member-) out conditions would appear to be no greater in an organization three times out of one hundred by chance, and we feel safe in rejecting the null hypothesis.

The average local League in the present study is characterized by a control curve with a negative slope; leaders tend to exercise more control than do the members as a group. While not universal, the negatively sloped curve is probably typical of the formal organizations which make up the fabric of American society. Industrial organizations are more extreme in this characteristic than are the voluntary Leagues of the present study. But many voluntary organizations, no doubt, con-

TABLE 4

PARTIAL CORRELATIONS BETWEEN INITIAL RATE OF QUESTIONNAIRE RETURNS (AS A CRITERION OF EFFECTIVENESS) AND ASPECTS OF Control in Leagues, Holding Size of League Constant

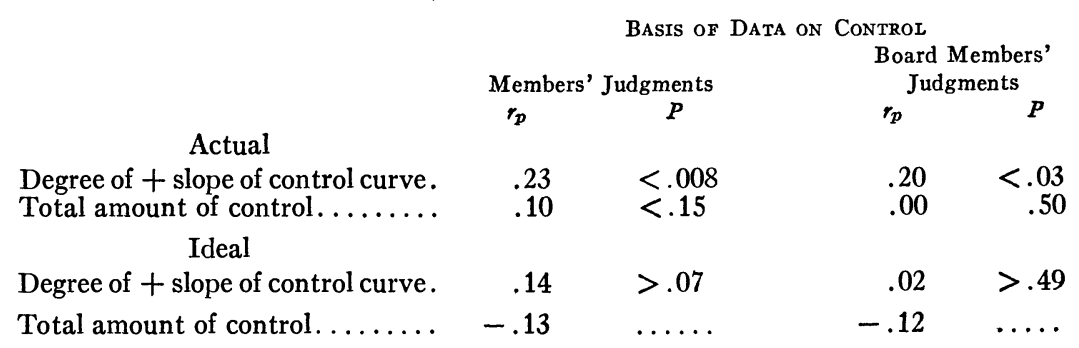

high in total control than in one which is low.

Partialing-out the effects of final rate of returns in addition to size lowers the correlation between slope (based on members' judgments) and initial rate of returns from .23 to $.18 .^{25}$ This correlation is small, but it would seem that in partialing-out final rate of returns we are applying a rather conservative test of the hypothesis. We are, in effect, considerably restricting the variance of the dependent variable, since final rate of returns and initial rate of returns correlate at .56. Nevertheless, a correlation as large as .18 would occur only

\footnotetext{
${ }^{25}$ Variations among Leagues in rate of questionnaire returns from Board members is negligible, since 95 per cent of sampled Board members completed and returned their questionnaires.
}

form to this pattern. ${ }^{26}$ The negative slope

${ }^{28}$ For control curves characterizing industrial organizations see Likert, "Influence and National Sovereignty," op. cit.; Floyd C. Mann and L. Richard Hoffman, Automation and the Worker: A Study of Social Change in Power Plants (New York: Henry Holt \& Co., 1960); Arnold S. Tannenbaum, "The Concept of Organizational Control," Journal of Social Issues, XII (1956), 50-60; Tannenbaum and Georgopoulos, op. cit.; and Lawrence K. Williams, L. Richard Hoffman, and Floyd C. Mann, "An Investigation of the Control Graph: Influence in a Staff Organization," Social Forces, XXXVII (March, 1959), 189-95. The League probably has a more active and influential membership than does the typical voluntary organization described by Blau (op. cit., p. 117) and by Philip Selznick (The Organization Weapon [New York: McGraw-Hill Book Co., 1952], p. 96). See also Sills, op. cit., and Paul M. Harrison, "Weber's Categories of Authority and Voluntary Associations," American Sociological Review, XXV (April, 
exists in the League in spite of the apparent desire of most members and leaders for a more positive distribution. Directing and sustaining the local League is a complex and difficult task. Translating the expressed wish for greater control by the members into the actual exercise of that control is fraught with problems, some of which can be seen as contributing to the development of an "oligarchic" (negatively sloped) distribution of control, and others to a laissez faire (low total control) pattern.

A number of circumstances may lead to the development of an "oligarchic" distribution of control. The president, for example, in an effort to get things done, may feel it necessary to make decisions herself rather than to put into motion a more cumbersome decision-making machinery. Or leaders may simply fail to communicate relevant information, thus depriving members of the necessary bases for decisionmaking. In some cases presidents may not sense clearly the distinction between those decisions which are appropriate to them and those which belong to the members, and they may unwittingly overstep their jurisdiction. Or leaders may assume too much regarding the directives they have from the members. They may act as if certain decisions have been made which, in fact, have not been made.

A number of conditions may contribute to the development of a laissez faire control structure. The loci of responsibility for exercising control may not be sufficiently well defined and responsibility may consequently fall between roles. The failure of mutual understandings relative to the appropriate loci of control may also lead to conflicts in which the efforts of one group

1960), 232-37. It is interesting to consider this general appraisal of voluntary organizations (other than the League) in the context of the hypothesis that voluntary associations in America have the function of providing "a sense of satisfaction with modern democratic processes because they help the ordinary citizen see how the processes function in limited circumstances" (Rose, op. cit., p. 51). cancel those of another; neither exercises much control. This implies the importance of a system of communication and interaction permitting the development of mutual understanding and influence. The success of attempts at influence may also depend upon the "bases of power" 27 and the attitudes of members toward each otherwhether or not members accept, trust, or like the persons exercising control, or whether or not the members exercising control have "expertness" or "legitimacy" or resources of reward or punishment at their disposal. The exercise of control is not likely to be widespread in an organization unless some of these characteristics are.

The data of this study support the hypothesis that local Leagues with less negatively sloped control curves tend to be more effective in their operations than are those with more negatively sloped curves. We have found some support for this hypothesis within the limits of a culture in which democratic values are extolled, among members who are interested in and somewhat sophisticated about the control of their organization, and within a voluntary organization which is not engaged in strenuous competition with other organizations and whose goals and products are relatively diffuse and intangible rather than specific and material. While these limits to generalization are implicit in the design of the study, the present results, together with those of earlier research in industrial settings, suggest a somewhat wider generality. ${ }^{28}$

Hypothesis 2 is partially supported by

${ }^{27}$ John R. P. French, Jr., and Burtram Raven, "The Bases of Social Power," in D. Cartwright (ed.), Studies in Social Power (Ann Arbor: Institute for Social Research, 1959), 150-67.

${ }^{28}$ See Coch and French, op. cit.; and Morse and Reimer, $o p$. cit. While Morse's and Reimer's experiment showed an increase in production under conditions of centralized control, it is doubtful that the increased productivity could have been maintained (see Rensis Likert, "Measuring Organizational Performance," Harvard Business Review, XXXVI [March-April, 1958], 41-50). 
the data. It should be considered a corollary of a more general hypothesis concerning the optimal amount of control necessary for effective organizational functioning. Although its generality was initially assumed to be limited to voluntary organizations and labor unions, an analysis of thirty-one industrial plants provides further support for the hypothesis and suggests broader generality. ${ }^{29}$ This hypothesis, however, may not apply to criteria of effectiveness in which the member is functioning away from the direct influence of other members or leaders.

An interesting question concerning the possible effects of differing combinations of height and slope of control curve is raised by the facts that each is related separately to effectiveness, that each can vary independently of the other, and that together they yield a somewhat higher degree of association with effectiveness. For example, while we would expect to find increases in the effectiveness of our Leagues corresponding to increases in slope, we would not expect effectiveness to go up if the increased slope is accompanied by a decrease in the height of the control curve. The more effective Leagues of our sample appear to be those characterized by a relatively high degree of positive slope and height of control curve.

While we have taken the data of this study as partially supportive of the original hypotheses, several limitations of design must be borne in mind. We cannot

\footnotetext{
${ }^{29}$ Likert, "Influence and National Sovereignty,"
} op. cit. rule out the possibility that members and board members may "see" patterns of control in their Leagues which do not exist in reality. Although we are inclined to doubt this possibility, members in effective Leagues may believe that their Leagues are more "democratic" than members of ineffective Leagues believe theirs to be when, in reality, no such difference exists. Nor can we answer with certainty the question of causality. It is clear, furthermore, that the independent-variable measures are not as reliable as we would like. But this fact operated against finding verification for our hypotheses. It should also be noted that the hierarchy within each League includes only three levels and that slope, under this condition, is equivalent to the difference in control exercised by the highest and lowest levels. Finally, the ranges of variation of our independent-variable measures are relatively narrow, and one might question the extent to which the hypothesized relationships would hold for more extreme values of slope and height of control curve. The data suggest, furthermore, that the effects of variations of one independent variable may be conditioned by the value of the other. Thus, increases in height of control curve among the Leagues of our sample appear to be associated with increases in effectiveness when degree of positive slope is relatively high, but not when it is low. Methodological refinement is called for, in addition to the retesting of the above hypotheses under varying organizational conditions.

UNIVERSITY OF MICHIGAN 